\title{
A phylogenetic framework of the legume genus Aeschynomene for comparative genetic analysis of the Nod-dependent and Nod-independent symbioses
}

Laurent Brottier $^{1 \dagger}$, Clémence Chaintreuil ${ }^{1 \dagger}$, Paul Simion², Céline Scornavacca², Ronan Rivallan ${ }^{3,4}$, Pierre Mournet ${ }^{3,4}$, Lionel Moulin ${ }^{5}$, Gwilym P. Lewis ${ }^{6}$, Joël Fardoux', Spencer C. Brown7, Mario Gomez-Pacheco ${ }^{7}$, Mickaël Bourges ${ }^{7}$, Catherine Hervouet ${ }^{3,4}$, Mathieu Gueye ${ }^{8}$, Robin Duponnois ${ }^{1}$, Heriniaina Ramanankierana ${ }^{9}$, Herizo Randriambanona ${ }^{9}$, Hervé Vandrot ${ }^{10}$, Maria Zabaleta ${ }^{11}$, Maitrayee DasGupta ${ }^{12}$, Angélique D'Hont ${ }^{3,4}$, Eric Giraud ${ }^{1}$ and Jean-François Arrighi ${ }^{* *}$

\begin{abstract}
Background: Among semi-aquatic species of the legume genus Aeschynomene, some have the property of being nodulated by photosynthetic Bradyrhizobium lacking the nodABC genes necessary for the synthesis of Nod factors. Knowledge of the specificities underlying this Nod-independent symbiosis has been gained from the model legume Aeschynomene evenia but our understanding remains limited due to the lack of comparative genetics with related taxa using a Nod factor-dependent process. To fill this gap, we combined different approaches to perform a thorough comparative analysis in the genus Aeschynomene.
\end{abstract}

Results: This study significantly broadened previous taxon sampling, including in allied genera, in order to construct a comprehensive phylogeny. In the phylogenetic tree, five main lineages were delineated, including a novel lineage, the Nod-independent clade and another one containing a polytomy that comprised several Aeschynomene groups and all the allied genera. This phylogeny was matched with data on chromosome number, genome size and lowcopy nuclear gene sequences to reveal the diploid species and a polytomy containing mostly polyploid taxa. For these taxa, a single allopolyploid origin was inferred and the putative parental lineages were identified. Finally, nodulation tests with different Bradyrhizobium strains revealed new nodulation behaviours and the diploid species outside of the Nod-independent clade were compared for their experimental tractability and genetic diversity.

Conclusions: The extended knowledge of the genetics and biology of the different lineages sheds new light of the evolutionary history of the genus Aeschynomene and they provide a solid framework to exploit efficiently the diversity encountered in Aeschynomene legumes. Notably, our backbone tree contains all the species that are diploid and it clarifies the genetic relationships between the Nod-independent clade and the Nod-dependent lineages. This study enabled the identification of A. americana and A. patula as the most suitable species to undertake a comparative genetic study of the Nod-independent and Nod-dependent symbioses.

Keywords: Aeschynomene, Genetics, Legumes, Nodulation, Phylogenetics, Polyploidy, Symbiosis

\footnotetext{
* Correspondence: jean-francois.arrighi@ird.fr

'Laurent Brottier and Clémence Chaintreuil contributed equally to this work.

'IRD, Laboratoire des Symbioses Tropicales et Méditerranéennes, UMR LSTM,

Campus International de Baillarguet, 34398 Montpellier, France

Full list of author information is available at the end of the article
}

(c) The Author(s). 2018 Open Access This article is distributed under the terms of the Creative Commons Attribution 4.0 International License (http://creativecommons.org/licenses/by/4.0/), which permits unrestricted use, distribution, and reproduction in any medium, provided you give appropriate credit to the original author(s) and the source, provide a link to the Creative Commons license, and indicate if changes were made. The Creative Commons Public Domain Dedication waiver (http://creativecommons.org/publicdomain/zero/1.0/) applies to the data made available in this article, unless otherwise stated. 


\section{Background}

In the field of nitrogen-fixing symbiosis, scientists have a long-standing interest in the tropical papilionoid legume genus Aeschynomene since the discovery of the ability of the species $A$. afraspera to develop abundant stem nodules [1]. This nodulation behavior is uncommon in legumes, being shared by very few hydrophytic species of the genera Discolobium, Neptunia and Sesbania, but it is exceptionally widespread among the semi-aquatic Aeschynomene species [2-4]. These stem-nodulating Aeschynomene species are able to interact with Bradyrhizobium strains that display the unusual property to be photosynthetic $[5,6]$. However, most outstanding is the evidence that some of these photosynthetic Bradyrhizobium strains lack both the $\operatorname{nod} A B C$ genes required for the synthesis of the key "Nod factors" symbiotic signal molecules and a type III secretion system (T3SS) that is known in other rhizobia to activate or modulate nodulation [7-9]. These traits revealed the existence of an alternative symbiotic process between rhizobia and legumes that is independent of the Nod factors.

As in the legume genus Arachis (peanut), Aeschynomene uses an intercellular symbiotic infection process instead of infection thread formation that can be found in other legume groups [10]. This lead to the suggestion that the Nod-independent process might correspond to the ancestral state of the rhizobial symbiosis although it cannot be excluded it corresponds to an alternative symbiotic interaction compared to the one described in other legumes [11-13]. It is noteworthy that all the Nod-independent species form a monophyletic clade within the Aeschynomene phylogeny and jointly they also display striking differences in the bacteroid differentiation process compared to other Aeschynomene species $[4,14]$. To decipher the molecular mechanisms of this distinct symbiosis, the Nod-independent $A$. evenia has been taken as a new model legume, because its genetic and developmental characteristics (diploid with a reasonable genome size $-2 \mathrm{n}=20,415 \mathrm{Mb} / 1 \mathrm{C}$-, short perennial and autogamous, can be hybridized and transformed) make this species tractable for molecular genetics [15-17]. Functional analyses revealed that some symbiotic determinants identified in other legumes (SYMRK, CCaMK, HK1 and DNF1) are recruited, but several key genes involved in bacterial recognition (e.g. $L Y K 3$ ), symbiotic infection (e.g. EPR3 and RPG), and nodule functioning (e.g. DNF2 and FEN1) were found not to be expressed in $A$. evenia roots and nodules, based on RNAseq data [14, 18-20]. This suggested that the Nod-independent symbiosis is distinct from the Nod-dependent one.

Forward genetics are now expected to allow the identification of the specific molecular determinants of the Nod-independent process in A. evenia [15, 19]. In addition, comparing $A$. evenia with closely related Nod-dependent Aeschynomene species will promote our understanding how the Nod-independent symbiosis evolved in Aeschynomene. The genus Aeschynomene (restricted now to the section Aeschynomene as discussed in [4]) is traditionally composed of three infrageneric taxa, subgenus Aeschynomene (which includes all the hydrophytic species) and subgenera Bakerophyton and Rueppellia [21, 22]. The genus has also been shown to be paraphyletic, a number of related genera being nested within, but altogether they form a distinct clade in the tribe Dalbergieae [4, 23-26]. Within this broad clade, two groups of semi-aquatic Aeschynomene have been well-studied from a genetic and genomic standpoint: the $A$. evenia group, which contains all the Nod-independent species (most of them being 2x), and the A. afraspera group (all species being Nod-dependent) that appears to have a $4 x$ origin [27-29]. For comparative analyses, the use of Nod-dependent species with a diploid structure would be more appropriate, but such Aeschynomene species are poorly documented.

To overcome these limitations, we aimed to produce a species-comprehensive phylogenetic tree supplemented with genetic and nodulation data. For this, we made use of an extensive taxon sampling in both the genus Aeschynomene and in closely related genera to capture the full species diversity of the genus and to clarify phylogenetic relationships between taxa. For most species, we also documented chromosome number, genome size and molecular data for low-copy nuclear genes, thus allowing the identification of diploid species as well as untangling the genome structure of polyploid taxa. In addition, these species were characterized for their ability to nodulate with various Bradyrhizobium strains containing or lacking nod genes and finally, the diploid species were submitted to a comparative analysis of their properties. In the light of the data obtained in this study, we propose two complementary Aeschynomene species to set a comparative genetic system with the $A$. evenia model.

\section{Results}

A comprehensive phylogeny of the genus Aeschynomene and allied genera

To obtain an in-depth view of the phylogenetic relationships within the genus Aeschynomene subgenus Aeschynomene, which contains the hydrophytic species, we significantly increased previous sampling levels by the addition of new germplasm accessions and, if these were not available, we used herbarium specimens. This strategy allowed checking the species identity and obtaining complementary data on the same plant material. DNA was isolated for 40 out of the 41 species (compared to the 27 species used in [4]) included in this group in 
taxonomic and genetic studies (Additional file 1: Table S1) $[4,21,27-29]$. In addition, to determine the phylogenetic relationship of this subgenus with Aeschynomene subgenera Bakerophyton and Rueppellia, unclassified Aeschynomene species, as well as with the allied genera Bryaspis, Cyclocarpa, Geissaspis, Humularia, Kotschya, Smithia and Soemmeringia, we also sampled all these 10 taxa (compared to the 5 taxa present in [4]) [23, 30]. This added 21 species to our total samples (Additional file 1: Table S1). The dalbergioid species Pictetia angustifolia was used as outgroup $[4,26]$.

Phylogenetic reconstruction of all the taxa sampled was undertaken using Bayesian analysis of the chloroplast $m a t K$ gene and the nuclear ribosomal ITS region that were processed separately (Additional file 2: Table S2, Additional file 3: Table S3). The matK and ITS sequences produced Bayesian trees that distinguished almost all the different Aeschynomene groups and related genera (Additional file 4: Figure S1; Additional file 5: Figure S2). The two phylogenetic trees have a very similar topology although some branches can be lowly supported in one of them. Incongruences were also observed for A. deamii and the genus Bryaspis, but the conflicting placements are lowly supported and so, they were interpreted as lack of resolution rather than hard incongruence. To improve the phylogenic resolution among the major lineages, the matK gene and the ITS sequence datasets were combined into a single phylogenetic analysis where only well-supported nodes were considered (posterior probability (PP) $\geq 0.5$ ) (Fig. 1). Our analysis recovered a grade of five main lineages with a branching order that received robust support ( $\mathrm{PP} \geq$ 0.92): (1) a basally branching lineage including $A$. americana, (2) an A. montevidensis lineage, (3) an A. evenia lineage corresponding to the Nod-independent clade $[15,27],(4)$ a new-identified lineage containing $A$. patula and (5) a lineage represented by an unresolved polytomy gathering the $A$. afraspera clade [19] and all the remaining taxa.

Our work also provided in the main good species-level resolution and it showed that Aeschynomene subgenus Aeschynomene (as currently circumscribed) is polyphyletic, being interspersed on the phylogenetic tree with the lineage containing A. patula, the two other subgenera of Aeschynomene and a number of other genera related to Aeschynomene (Fig. 1) [4, $24,26,31]$. The combined analysis also grouped the genus Bryaspis with the species related to $A$. afraspera in a highly supported clade but it remained inconclusive regarding its exact positioning as previously observed in a trnL-based phylogeny (Fig. 1) [4]. Most noticeably, several intergeneric relationships are consistently revealed, notably between Cyclocarpa and Smithia as well as in the clade containing Aeschynomene subgenera Bakerophyton and Rueppellia together with the genus Humularia (referred to as the BRH clade herein after) (Fig. 1). This clade supports previous observations of a morphological continuum between Aeschynomene subgenus Rueppellia and the genus Humularia and brings into question their taxonomic separation [22].

\section{Ploidy level of the species and origin of the polyploid lineages}

The revised Aeschynomene phylogeny was used as a backbone tree to investigate the genetic status of the different species and the evolution of ploidy levels. Previous studies had demonstrated that the A. evenia clade is mostly diploid $(2 \mathrm{n}=2 \mathrm{x}=20)$ even if some species such as $A$. indica $(2 \mathrm{n}=4 \mathrm{x}=40,2 \mathrm{n}=6 \mathrm{x}=60)$ appear to be of recent allopolyploid origin [27, 29]. Conversely, all the species of the $A$. afraspera group were found to be polyploid $(2 \mathrm{n}=4 \mathrm{x}=28,38,40,2 \mathrm{n}=8 \mathrm{x}$ $=56,76)$ and to have a common $A B$ genome structure but the origin of the polyploidy event remained undetermined [28]. To assess the ploidy levels in Aeschynomene species and related genera, chromosome numbers and nuclear DNA content were determined (appended to labels in Fig. 2 a, Additional file 1: Table S1, Additional file 6: Figure S3 and Additional file 7: Figure S4). We evidenced the lineages containing $A$. americana, A. montevidensis, A. evenia and A. patula, as well as Soemmeringia semperflorens, to be diploid with $2 \mathrm{n}=20$, with the smallest $2 \mathrm{x}$ genome for $A$. patula $(0.58 \mathrm{pg} / 2 \mathrm{C})$ and the largest $2 \mathrm{x}$ genome for $A$. deamii $(1.93 \mathrm{pg} / 2 \mathrm{C})$. With the exception of $S$. semperflorens, all the groups that are part of the polytomy were characterized by higher chromosome numbers. These chromosome numbers equate to approximately twice the one present in diploid species (except for $2=28$ ), suggesting that the corresponding groups are most probably polyploid. Putatively polyploid species with chromosome numbers departing from $2 \mathrm{n}=40$ are likely to be of disploid origin as already described in the $A$. afraspera clade [28]. Here again, important genome size variations ranging from $0.71 \mathrm{pg} / 2 \mathrm{C}$ for the Geissaspis species to $4.82 \mathrm{pg} / 2 \mathrm{C}$ for the $4 \mathrm{x} A$. schimperi highlight the genomic differentiation of the various taxa (Fig. 2 a, Additional file 1: Table S1).

To firmly link chromosome numbers to ploidy levels and to clarify genetic relationships between the different lineages, we cloned and sequenced four nuclear-encoded low-copy genes in selected species: CYP1 (Cyclophilin 1), eiF1 $\alpha$ (eukaryotic translation initiation factor $\alpha$ ), SuSy (Sucrose Synthase) and TIP1;1 (tonoplast intrinsic protein 1;1) (Additional file 2: Table S2). For all diploid species, only one gene sequence was obtained, while for all the polyploid species, in almost all cases, a pair of putative homeologues was isolated, thus confirming their 


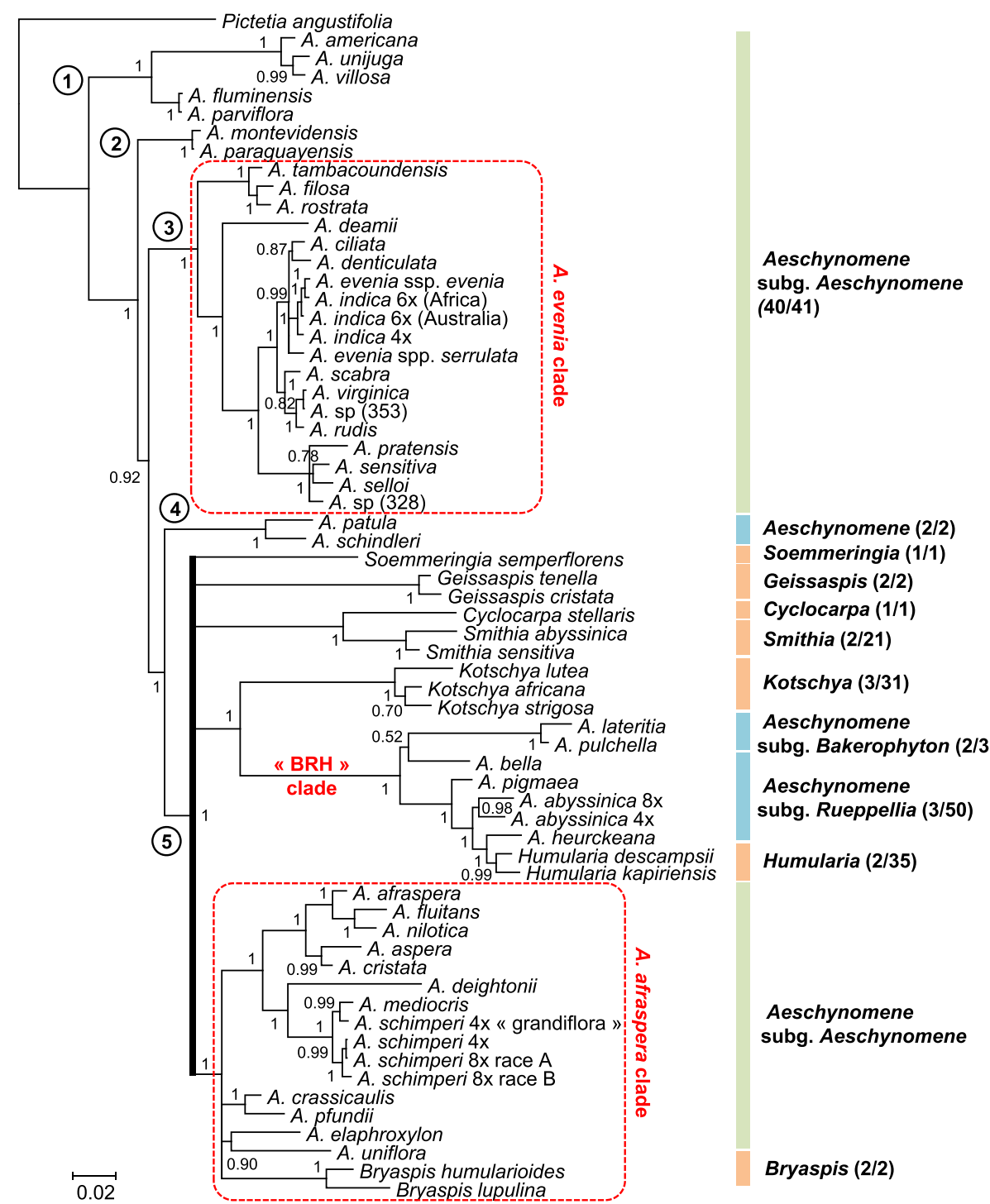

Fig. 1 Phylogeny of the genus Aeschynomene and allied genera. The Bayesian phylogenetic reconstruction was obtained using the concatenated ITS (Internal Transcribed Spacer) + matK sequences. Numbers at branches indicate posterior probability above 0.5. The five main lineages are identified with a circled number and the two previously studied Aeschynomene groups are framed in a red box bordered with a dashed line. On the right are listed Aeschynomene subgenus Aeschynomene (in green), other Aeschynomene subgenera or species groups (in blue) and related genera (in orange) with numbers of sampled species/total species indicated into parenthesis

genetic status inferred from the karyotypic data (Additional file 3: Table S3). In general, the duplicated copies were highly divergent and nested in two different major clades in the resulting Bayesian phylogenic trees generated for each gene (Additional file 8: Figure S5). One clade contained all the A copies (except for one anomalous sequence for B. lupulina in the eiF1 $\alpha$ tree) and the other clade gathered all the $B$ copies previously identified in A. afraspera [28]. These two clades A and B do not always receive high support, however it is notable that the A copies formed a monophyletic group with, or sister to, the A. patula sequence and similarly the B copies with, or sister to, the $S$. semperflorens sequence, in all gene trees (Additional file 8: Figure S5). In an attempt to improve phylogenetic resolution, the four gene data sets were concatenated. This combination resulted in a highly supported Bayesian tree that places the A copy clade as the sister to the diploid A. patula ( $\mathrm{PP}=1)$, and the B copy clade as sister to the diploid S. semperflorens $(\mathrm{PP}=1)$ (Fig. 2 b). As a result, these phylogenetic analyses combined to karyotypic data show that all the five main lineages contain diploid species. They also reveal that all the polyploid groups share the same $\mathrm{AB}$ genome structure, with the diploid A. patula and S. semperflorens species being the modern representatives of the ancestral donors of the $\mathrm{A}$ and $\mathrm{B}$ genomes. 


\section{a ITS + matK}

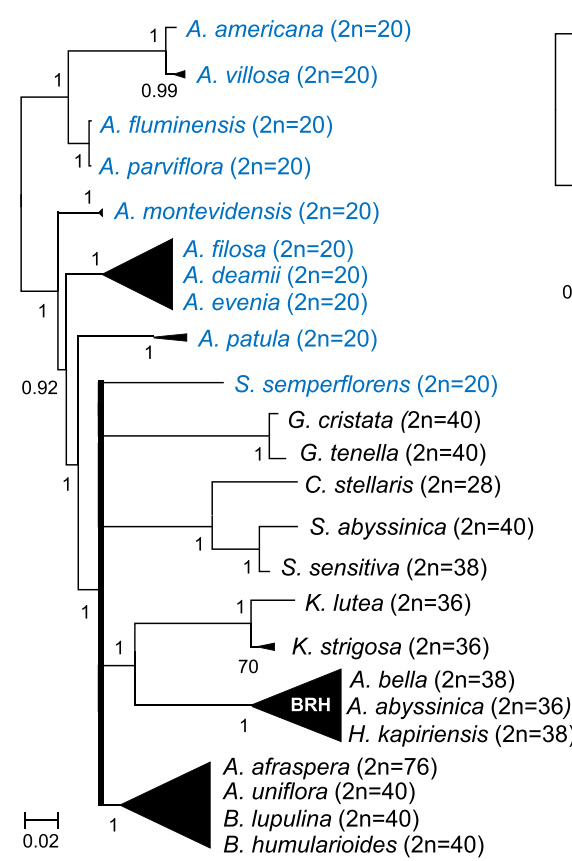

\section{Phylogenetic network}

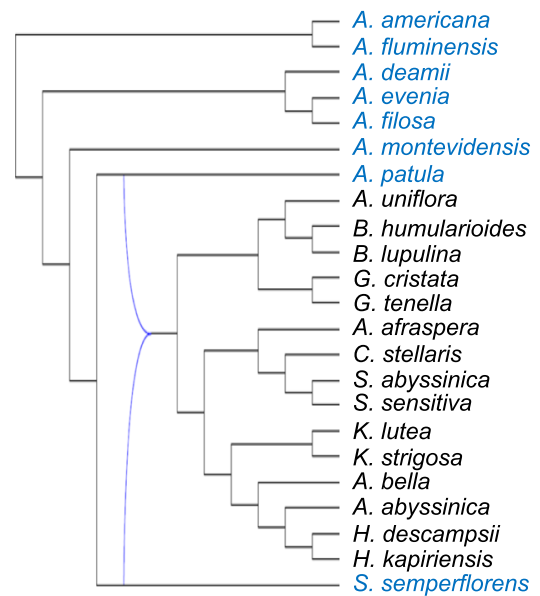

b Concatenated nuclear genes

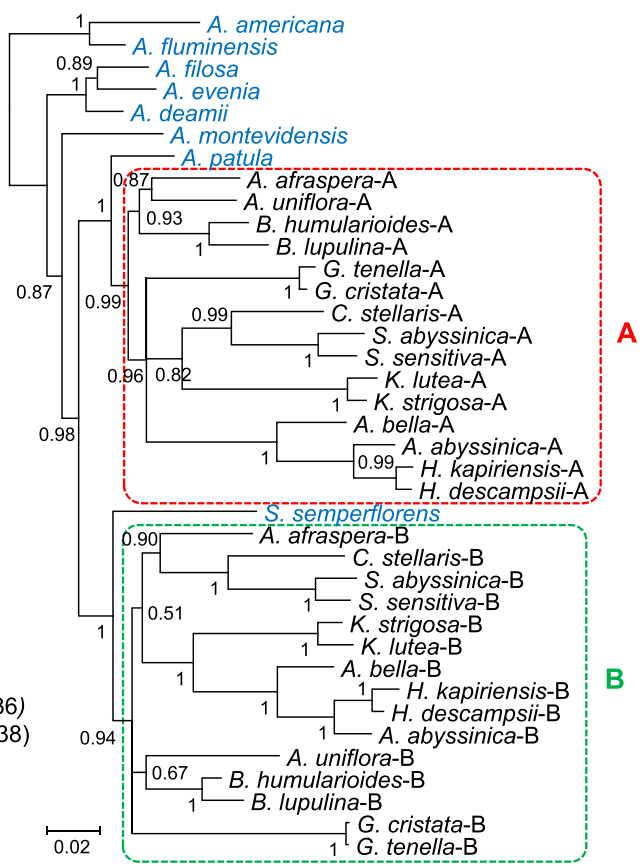

A

Fig. 2 Genomic characteristics and phylogenetic relationships. a Simplified Bayesian ITS + matK phylogeny with representative species of different lineages and groups. The A. evenia, A. afraspera and BRH (Bakerophyton-Rueppelia-Humularia) clades are represented by black triangles and the polytomy is depicted in bold. Chromosome numbers are indicated in brackets. $\mathbf{b}$ Phylogenetic relationships based on the combination of 4 concatenated nuclear low-copy genes (CYP1, eifla, SuSy and TIP1;1 genes detailed in Additional file 8: Figure S5). Diploid species (2n=20) are in blue, polyploid species $(2 n \geq 28)$ in black. The A and B subgenomes of the polyploid taxa are delineated by red and green boxes in dashed lines, respectively. Nodes with a posterior probability inferior to 0.5 were collapsed into polytomies. Posterior probability above 0.5 are indicated at every node. c The one-allopolyploidation hypothesis (N1-best) obtained with the phylogenetic network analysis based on the T2 tree with reticulations in blue (detailed in Additional file 10: Figure S7)

In addition, an ancestral state reconstruction analysis performed on the ITS + matK phylogeny indicates that diploidy is the ancestral condition in the whole revised group and that tetraploidy most likely evolved once in the polytomy (Additional file 9: Figure S6). To provide support on a probable single origin of the allopolyploidy event, separate and concatenated nuclear gene trees were further used for a phylogenetic network analysis. In this analysis, the two non-allopolyploidisation hypotheses (T1 and T2) were found to be more costly (scores of 207 and 196) than the two hypotheses allowing for hybridization (N1-best and N2-best with scores of 172 and 169, respectively) (Additional file 10: Figure S7a-d). The one-allopolyploidisation hypothesis (N1-best) strongly 
indicates that a hybridization between $A$. patula and $S$. semperflorens gave rise to the polyploid lineages as inferred above (Fig. 2c, Additional file 10: Figure S7c). Although the two-allopolyploidisation hypothesis (N2-best) yielded the absolute best score, the score improvement was very low (169 vs 172) and the resulting network included the hybridization inferred with the one-allopolyploidisation hypothesis making this latter hypothesis most probably the correct one (Additional file 10: Figure S7d).

\section{Nodulation properties of the different Aeschynomene lineages}

Species of Aeschynomene subgenus Aeschynomene are known to be predominantly amphibious and more than 15 of such hydrophytic species (found in the A. evenia and $A$. afraspera clades, as well as $A$. fluminensis) have been described as having the ability to develop stem nodules [3, 21, 28, 32]. In A. fluminensis, these nodules are observed only in submerged conditions (as also seen in the legume Discolobium pulchellum), while they occur on aerial stems within the $A$. evenia and $A$. afraspera clades (Fig. 3 a) [4, 33-35]. Phenotypic analysis of representatives of the different lineages under study revealed that they all display adventitious root primordia along the stem (Fig. 3 a,b). Adventitious roots are considered to be an adaptation to temporary flooding and they also correspond to nodulation sites in stem-nodulating Aeschynomene species (Fig. 3 b) [35]. Given that the $A$. evenia and $A$. afraspera clades are now demonstrated to have different genomic backgrounds provides a genetic argument for independent developments of stem nodulation by photosynthetic bradyrhizobia. Reconstruction of ancestral characters based on the ITS + matK phylogeny confirmed that the whole group was ancestrally of wet ecology and endowed with adventitious root primordia but that the stem nodulation ability evolved several times as previously inferred (Additional file 11: Figure S8; Additional file 12: Figure S9; Additional file 13: Figure S10) [4, 28].

To investigate whether the newly studied species could be nodulated by photosynthetic bradyrhizobia, we extended the results obtained by Chaintreuil et al. [4] by testing the nodulation abilities of 22 species available (listed in Fig. 4 a) for which sufficient seeds were available. Three different strains of Bradyrhizobium equating to the three cross-inoculation (CI) groups defined by Alazard [2] were used: DOA9 (non-photosynthetic Bradyrhizobium of CI-group I), ORS285 (photosynthetic Bradyrhizobium with nod genes of CI-group II) and ORS278 (photosynthetic Bradyrhizobium lacking nod genes of CI-group III). These strains were used to inoculate the 22 species and their ability to nodulate them was analyzed at $21 \mathrm{dpi}$. For this, we recorded nodule formation and compared nitrogen fixation efficiency by an acetylene reduction assay (ARA) and observation of plant vigor. Nodulation was observed on all species tested except for $S$. sensitiva that had problem of root development, for A. montevidensis and S. semperflorens. For these three species, either the culture conditions or the Bradyrhizobium strains used were not appropriate (Fig. 4 a).

The non-photosynthetic strain DOA9 displayed a wide host spectrum but was unable to nodulate the Nod-independent species, $A$. deamii, A. evenia and $A$. tambacoundensis. The photosynthetic strain ORS285 efficiently nodulated $A$. afraspera and the Nod-independent Aeschynomene species (Fig. 4 a), as previously reported [4]. Interestingly, the ORS285 strain was also able to induce nitrogen-fixing nodules in $A$. patula and ineffective nodules were observed on A. fluminensis and the genera Bryaspis, Cyclocarpa and Smithia (Fig. 4 a). To examine if in these species the nodulation process relies on a Nod-dependent or Nod-independent symbiotic process, we took advantage of the availability of a $\Delta n o d$ mutant of the strain ORS285. None of them were found to be nodulated by ORS285 $\triangle$ nod, suggesting that the nodule formation depended on a Nod signaling in these species (Fig. 4 a). As a matter of fact, the ORS285 nnod mutated strain was found to be able to nodulate only species of the $A$. evenia clade similarly as to the photosynthetic strain ORS278 naturally lacking nod-genes (Fig. 4 a). Analysis of the evolution of these nodulation abilities by performing an ancestral state reconstruction on the revisited phylogeny indicated several emergences of the ability to interact with photosynthetic bradyrhizobia and a unique emergence of the ability to be nodulated by the nod gene-lacking strain as observed earlier (Additional file 14: Figure S11; Additional file 15: Figure S12) [4]. Finally, from these nodulation tests, different nodulation patterns emerged for the diploid Aeschynomene species (as detailed in Fig. 4 b-d) with the DOA9 and ORS278 strains being specific to the Nod-dependent and Nod-independent groups respectively and ORS285 showing a gradation of compatibility between both.

\section{Diversity of the diploid species outside the nod- independent clade}

To further characterize the diploid species that fall outside of the Nod-independent clade, in which $A$. evenia relies, they were analyzed for their developmental properties and genetic diversity (Fig. 5 a). All species are described as annual or short perennial [21, 30, 31]. While A. americana, A. villosa, A. fluminensis, A. parviflora and $A$. montevidensis are robust and erect, reaching up to $2 \mathrm{~m}$ high when mature similarly as to $A$. evenia, $A$. patula and S. semperflorens are creeping or decumbent herbs. These differences in plant habit is reflected by the important variation in seed size between these two groups (Fig. 5 a). This has an impact on plant 


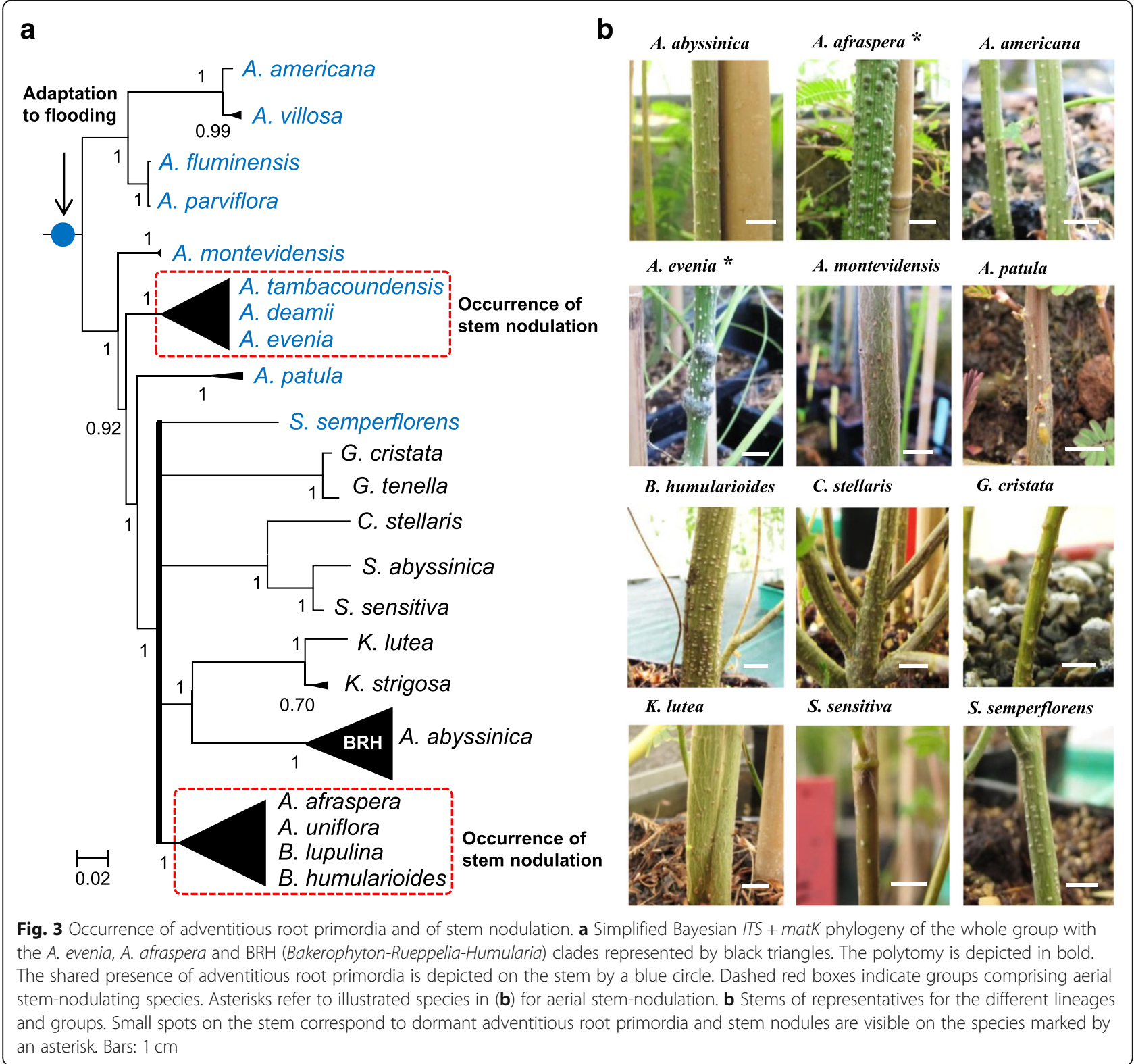

manipulation since for A. patula and S. semperflorens seed scarification needs to be adapted $(25 \mathrm{~min}$ with concentrated sulfuric acid instead of $40 \mathrm{~min}$ for the other species) and in vitro plant growth takes slightly more time to get a root system sufficiently developed for inoculation with Bradyrhizobium strains (10 days-post-germination instead of the 5-7 dpi for other species) [15]. Consistent flowering and seed production was observed for A. americana, A. villosa, A. patula and $S$. semperflorens when grown under full ambient light in the tropical greenhouse in short days conditions as previously described for A. evenia, making it possible to develop inbred lines by successive selfing (Fig. 5 a) [15]. For A. fluminensis, $A$. parviflora and $A$. montevidensis, flowering was sparse or not observed, indicating that favorable conditions for controlled seed set were not met (Fig. 5 a).

Five species (A. villosa, A. fluminensis, A parviflora, A. montevidensis and $S$. semperflorens) are strictly American while $A$. americana is a pantropical species and $A$. patula is endemic to Madagascar [21, 31, 32]. Several species have a narrow geographic distribution or seem to be infrequent, explaining the very limited accession availability in seedbanks (Fig. 5 a) [21, 31, 32]. This is in sharp contrast with both A. americana and $A$. villosa that are well-collected, being widely found as weedy plants and sometimes used as component of pasture for cattle (Fig. 5 a) [36]. To assess the genetic diversity of these two species, a germplasm collection containing 79 accessions for A. americana and 16 


\section{a}

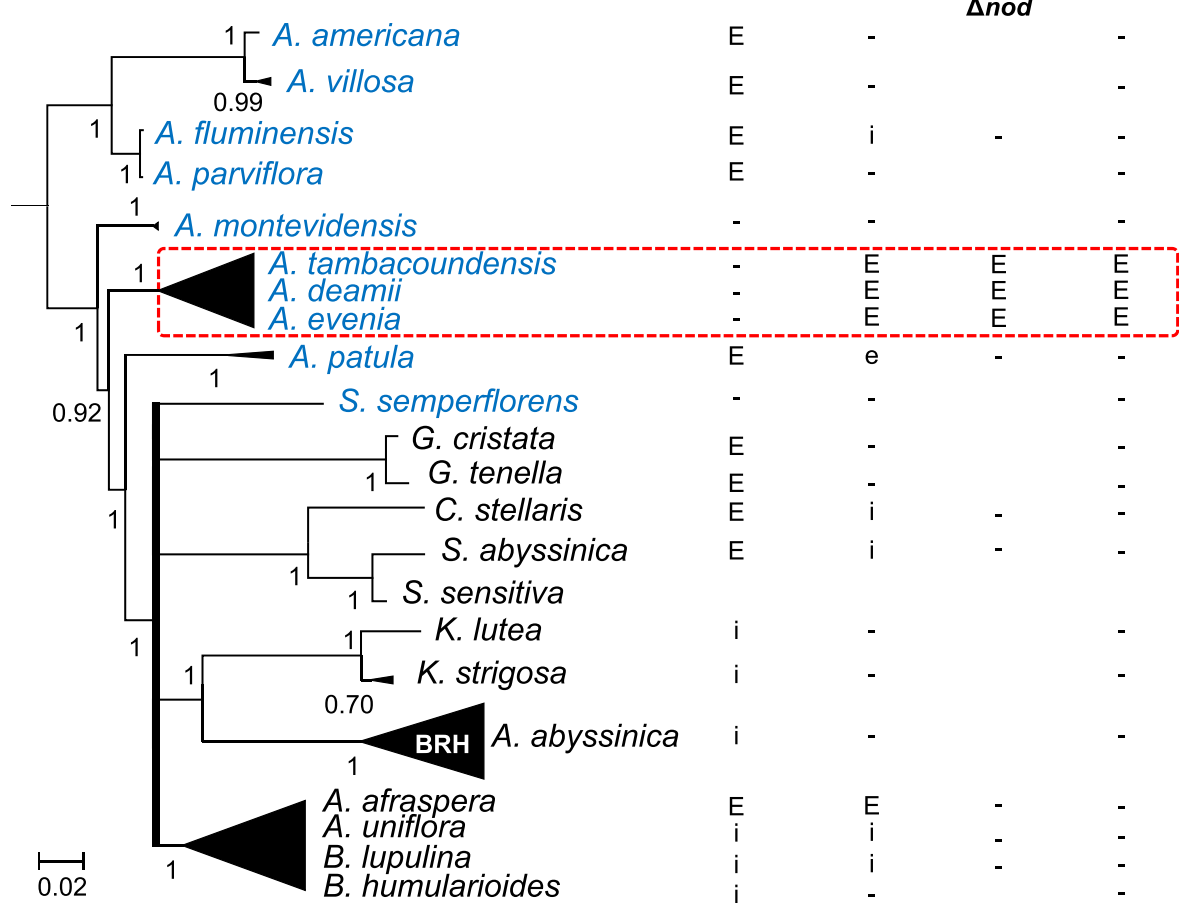

b

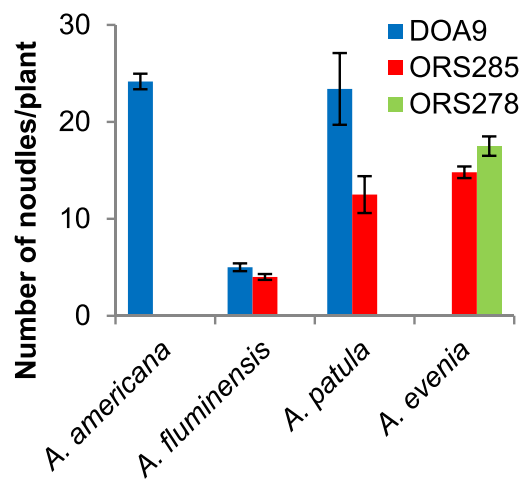

d
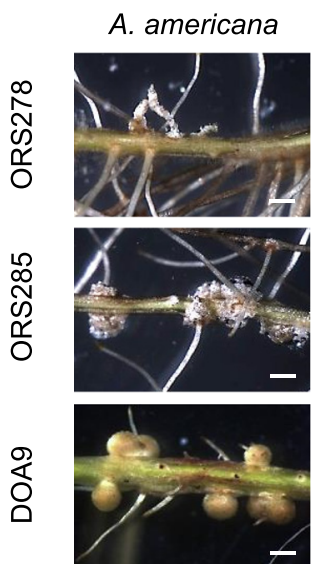

C

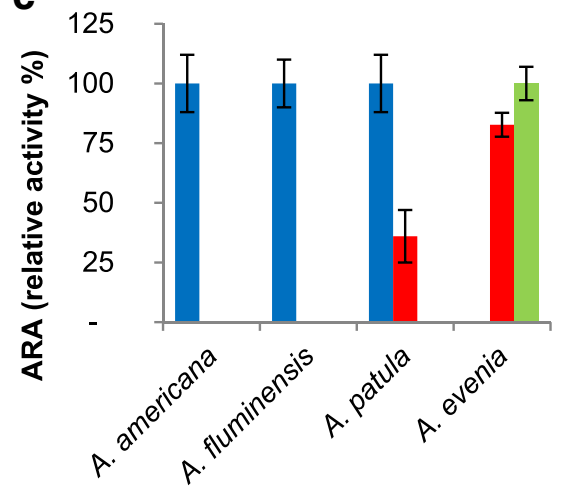

A. fluminensis
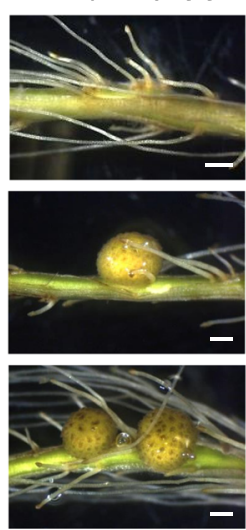

A. evenia
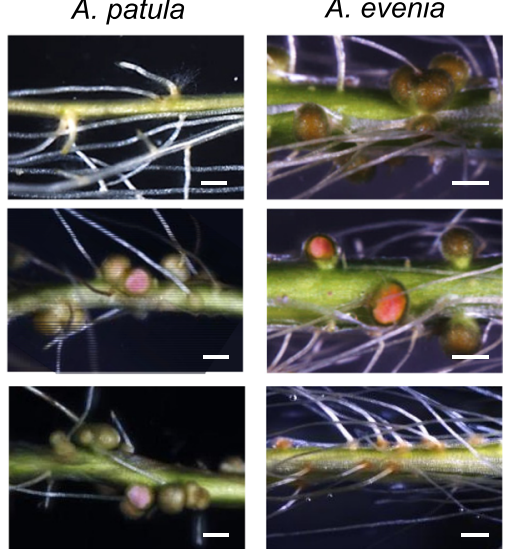

Fig. 4 (See legend on next page.) 
(See figure on previous page.)

Fig. 4 Comparison of the root nodulation properties. a Species of different lineages and groups that were tested for nodulation are listed in the simplified Bayesian phylogeny on the left. Root nodulation tests were performed using the DOA9, ORS285, ORS285 $\triangle$ nod and ORS278 strains. E, effective nodulation; e, partially effective nodulation; i, ineffective nodulation, -, no nodulation; blank, not tested. b Number of nodules per plant, c relative acetylene-reducing activity (ARA) and $\mathbf{d}$ aspect of the inoculated roots developing nodules or not (some nodules were cut to observe the leghemoglobin color inside) after inoculation with Bradyrhizobium DOA9, ORS285 and ORS278 on A. americana, A. patula, A. afraspera and A. evenia. Error bars in (b) and (c) represent s.d. $(n=6)$. Scale bar in $(\mathbf{d}): 1 \mathrm{~mm}$

accessions for A. villosa, and spanning their known distribution was used (Additional file 16: Table S4). A Genotyping-By-Sequencing (GBS) approach resulted in 6370 and 1488 high quality polymorphic SNP markers for A. americana and A. villosa accessions, respectively. These two SNP datasets subsequently served for a clustering analysis based on the multidimensional-scaling
(MSD) method. The MSD analysis distinguished three major groups of accessions for both $A$. americana and A. villosa along coordinate axes 1 and 2 (Fig. 5 b). When mapping the accessions globally, the three groups identified for A. villosa were observed conjointly in Mexico and only the group (3) extended to the northern part of South America (Fig. 5c, Additional file 16: Table S4).

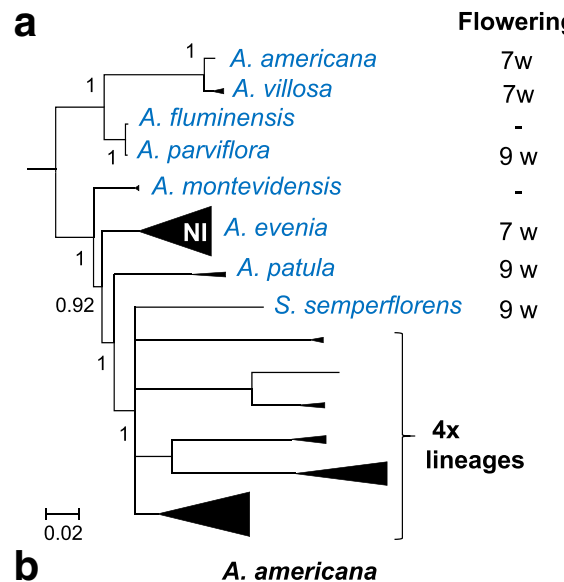

$\begin{array}{cccc}\text { Seed set } & \text { Seed size } & \text { Distribution } & \text { Germplasm } \\ \text { Profuse } & 2.5-4 \mathrm{~mm} & \text { Pantropical } & 693 \\ \text { Profuse } & 2.5-4 \mathrm{~mm} & \text { American } & 150 \\ - & 2.9 \mathrm{~mm} & \text { American } & 5 \\ \text { Few pods } & 2.6 \mathrm{~mm} & \text { American } & 1 \\ - & 3.7 \mathrm{~mm} & \text { American } & 1 \\ \text { Profuse } & 3 \mathrm{~mm} & \text { American- } & 67 \\ \text { Profuse } & 1.5 \mathrm{~mm} & \text { African } & 1 \\ \text { Profuse } & 1.3 \mathrm{~mm} & \text { American } & 1 \\ & & & \\ & & & \text { African- } \\ & & & \text { Asian }\end{array}$
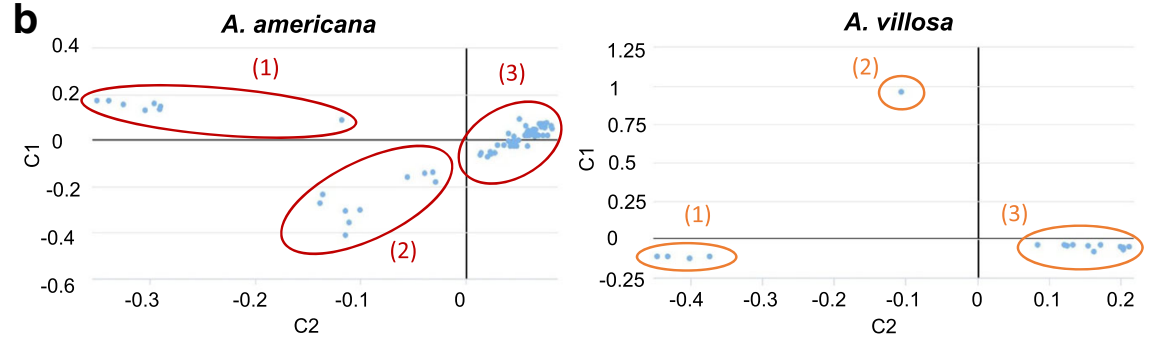

C

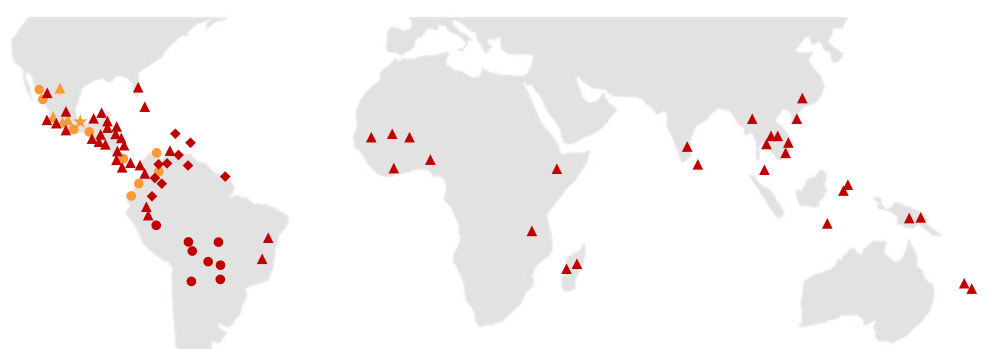

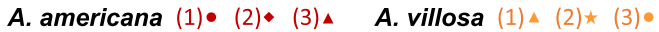

Fig. 5 Characteristics of diploid species. a Development and germplasm data for species that are listed in the simplified phylogeny on the left. A. evenia from the Nod-independent clade (NI) is also included for comparison. Germplasm numbers correspond to the sum of accessions available at CIAT, USDA, Kew Gardens, AusPGRIS, IRRI and at LSTM. b Multi-dimensional scaling (MSD) plots of the genetic diversity among A. americana (left) and A. villosa (right) accessions according to coordinates 1 and 2 (C1, C2). Identified groups are delimited by circles and labeled with numbers. $\mathbf{c}$ Geographical distribution of the of the A. americana and A. villosa accessions. Taxon colours and group numbers are the same as in (b). Details of the accessions are provided in Additional file 16: Table S4. Word map from https://pixabay.com 
Contrarily, a clear geographical division was observed for A. americana with the group (1) occupying the central part of South America, group (2) being found in the upper part of South America while group (3) was present in distinct regions from Mexico to Brazil and in all the Paleotropics (Fig. 5c, Additional file 16: Table S4). $A$. americana is hypothesized to be native in America and naturalized elsewhere [36]. The observed distributions in combination with the fact that in the MSD analysis accessions are tightly clustered in group (3) compared to groups (1) and (2) support this idea and indicate that its group (3) recently spread worldwide.

\section{Discussion}

\section{A well-documented phylogenetic framework for the legume genus Aeschynomene}

We produced a new and comprehensive phylogeny of the genus Aeschynomene and its closely related genera complemented by gene data sets, genome sizes, karyotypes and nodulation assays. For plant genera, they are few for which documentation of taxonomic diversity is that extensive and supported by a well-resolved, robustly supported phylogeny so as to reveal the evolutionary history of these groups [37]. Here, the whole group, which includes the genus Aeschynomene with its 3 subgenera and its 7 allied genera, is evidenced to comprise five main lineages, including the Nod-independent clade, with diploid species that could be found in all these lineages. The multigene data analysis provided robust evidence that two of them, represented by the two diploid species A. patula and S. semperflorens, are involved in an ancient allotetraploidization process that gave rise to the different polyploid lineages clustering in a polytomy. Separate allopolyploidization events from the same diploid parents or a single allopolyploid origin are plausible explanations for the formation of these lineages. However, the consistent resolution of the phylogenetic tree obtained with the combined gene data, where A. patula and S. semperflorens are sisters to the A and B subgenomic sequences, favours the hypothesis of a single allopolyploid origin, as also argued for other ancient plant allopolyploid events in Asimitellaria (Saxifragaceae) and Leucaena (Leguminosae) [37, 38]. The phylogenetic network analysis also supports the one-allopolyploidisation hypothesis. However, additional nuclear genes will be needed to conclusively confirm that no additional hybridization event occurred. Although not the focus of the present study, it is worth noting that most diploid species are found in the Neotropics, the two modern representatives of the $\mathrm{A}$ and $\mathrm{B}$ genome donors that gave rise to the $4 \mathrm{x}$ lineages are located on different continents (S. semperflorens in South America and A. patula in Madagascar) and that all the $4 \mathrm{x}$ lineages are located in the
Paleotropics [30]. This raises questions about the evolution of the whole group and the origin of the $4 \mathrm{x}$ lineages. In addition, the presence of a polytomy suggests that this allopolyploid event preceded a rapid and major diversification of $4 \mathrm{x}$ groups that have been ascribed to different Aeschynomene subgenera or totally distinct genera that altogether represent more than $80 \%$ of the total species of the whole group [26, 39]. Diversification by allopolyploidy occurred repeatedly in the genus Aeschynomene since several neopolyploid species were evidenced in both the $A$. evenia clade and the $A$. afraspera clade as exemplified by $A$. indica $(4 \mathrm{x}, 6 \mathrm{x})$ and $A$. afraspera $(8 \mathrm{x})$ [27, 28]. Dense sampling for several Aeschynomene taxa or clades also allowed delimiting more precisely species boundaries (for morphologically similar taxa but which are genetically differentiated or correspond to different cytotypes) and evidencing intraspecific genetic diversity that is often geographically-based as showed for the pantropical species A. americana (this study), A. evenia, $A$. indica and $A$. sensitiva [29]. All these Aeschynomene share the presence of adventitious root primordia on the stem that correspond to the infection sites for nodulation. The ever-presence of adventitious root primordia in all taxa of the whole group and an ancestral state reconstruction substantiate the two-step model proposed earlier for the evolution of stem nodulation in Aeschynomene with a common genetic predisposition at the base of the whole group to produce adventitious root primordia on the stem, as an adaptation to flooding, and subsequent mutations occurring independently in various clades to enable stem nodulation [4]. The ability to interact with photosynthetic bradyrhizobia that are present in aquatic environments also appear to have evolved at least 3 times [ 4 and this work, Fig. 4]. This photosynthetic activity is important for the bacterial symbiotic lifestyle as it provides energy usable for infection and subsequently for nitrogenase activity inside the stem nodules [5]. To date, natural occurrence of nodulation by photosynthetic bradyrhizobia has been reported only for the $A$. evenia and $A$. afraspera clades, and for A. fluminensis $[6,34,40]$. Nevertheless, we could not test the photosynthetic strains isolated from $A$. fluminensis nodules and the nature of the strains present in those of the newly studied species $A$. patula has not been investigated yet. They would allow the comparison of their nodulation efficiency with the reference photosynthetic Bradyrhizobium ORS278 and ORS285 strains. In addition, we can ask if the semi-aquatic lifestyle and/or nodulation with photosynthetic bradyrhizobia may have facilitated the emergence of the Nod-independent symbiosis in the A. evenia clade.

\section{Aeschynomene species for a comparative analysis of nodulation with $A$. evenia}

To uncover whether the absence of detection for several key symbiotic genes in the root and nodule 
transcriptomic data of $A$. evenia are due to gene loss or inactivation, and to identify the specific symbiotic determinants of the Nod-independent symbiosis, a genome sequencing combined to a mutagenesis approach is presently being undertaken for A. evenia in our laboratory. A comparative analysis with Nod-dependent Aeschynomene species is expected to consolidate this genomic and genetic analysis performed in A. evenia by contributing to elucidate the genetic changes that enabled the emergence of the Nod-independent process. Phylogenomics and comparative transcriptomics, coupled with functional analysis, are undergoing increased development in the study of symbiosis to unravel gene loss linked to the lack of developing a symbiosis but also to identify new symbiosis genes (for arbuscular mycorrhizal symbiosis [41, 42]; for the nodulating symbiosis $[43,44])$. Comparative work on symbiotic plants is often hindered, however, either by the absence of closely related species which display gain or loss of symbiotic function or, when these are present, by the lack of well-understood genetic framework, as outlined in $[10,43,45,46]$. In fact, such situations are few, but in the case of the nodulating Parasponia/non-nodulating Trema system, a fine comparative analysis was very powerful to evidence a parallel loss of the key symbiotic genes NFP2, NIN and RGP, in the non-nodulating species, challenging the long-standing assumption that Parasponia specifically acquired the potential to nodulate [45-47]. In this respect, the uncovering of the genetic evolution of the genus Aeschynomene and related genera along with the identification of diploid species outside of the Nod-independent clade, provided a robust phylogenetic framework that can now be exploited to guide the choice of Nod-dependent diploid species for comparative genetic research. Among them, some species are discarded because of major inconveniences such the lack of nodulation with reference Bradyrhizobium strains or the inability to produce seeds in our greenhouse conditions. Based on both efficient nodulation, short flowering time and the ease of seed production, A. americana $(2 \mathrm{n}=20,600 \mathrm{Mb})$ and $A$. patula $(2 \mathrm{n}=20,270 \mathrm{Mb})$ appear to be the most promising Nod-dependent diploid species to develop a comparative genetic system with A. evenia $(2 \mathrm{n}=20,400$ $\mathrm{Mb})$. In contrast to A. evenia, A. americana is nodulated only by non-photosynthetic bradyrhizobia and in this respect, it behaves similarly as to other legumes. This species is widespread in the tropics, hundred of germplasm being available, and it has already been subject to research studies notably to isolate its nodulating Bradyrhizobium strains, among which the DOA9 strain $[48,49]$. As $A$. americana belongs to the most basal lineage in the Aeschynomene phylogeny, it may be representative of the ancestral symbiotic mechanisms found in the genus. On the other hand, A. patula has a restricted Malagasy distribution with only one accession available, but it has the interest to be relatively smaller both in plant size and in genome size (actually the smallest diploid genome in the group) making this species the "arabidopsis" of the Aeschynomene. Like A. americana, this species is efficiently nodulated by non-photosynthetic bradyrhizobia, but it is also compatible with the photosynthetic nod gene-containing ORS285 strain. This property makes this species particularly interesting as it allows direct comparisons of mechanisms and pathways between $A$. evenia and $A$. patula without the problem of potential strain effects on symbiotic responses. In addition, when considering the Aeschynomene phylogeny, A. patula is closer to A. evenia than A. americana is, and so it may be more suitable to illuminate the changes necessary to switch a Nod-dependent to a Nod-independent process or vice-versa.

\section{Conclusions}

In the present study, we established a comprehensive and robust molecular phylogeny for the genus Aeschynomene and related genera, documented with molecular, genomic and nodulation data, in order to unravel the evolutionary history of the whole group. This phylogenetic framework provides support to exploit efficiently the genetic and nodulation diversity encountered in Aeschynomene legumes. In the present study, it guided the choice of $A$. americana and $A$. patula, as the two most appropriate Nod-dependent diploid species to develop a comparative genetic system with the Nod-independent $A$. evenia model. Developing sequence resources and functional tools for A. americana and/or A. patula is now necessary to set up a fully workable comparative Aeschynomene system. In the long run, handling such a genetic system will be instrumental in understanding how photosynthetic Bradyrhizobium and some Aeschynomene species co-evolved and in unravelling the molecular mechanisms of the Nod-independent symbiosis.

\section{Methods}

\section{Plant material}

All the accessions of Aeschynomene used in this study, including their geographic origin and collection data are listed in Additional file 1: Table S1 and Additional file 16: Table S4. Seed germination and plant cultivation in the greenhouse were performed as indicated in Arrighi et al. [15]. Phenotypic traits such as the presence of adventitious root primordia and nodules on the stem were directly observed in the glasshouse.

\section{Nodulation tests}

Nodulation tests were carried out using Bradyrhizobium strains ORS278 (originally isolated from A. sensitiva 
nodules), ORS285 (originally isolated from A. afraspera nodules), ORS285 $\Delta$ nod and DOA9 (originally isolated from $A$. americana nodules) [7, 49, 50]. Bradyrhizobium strains were cultivated at $34{ }^{\circ} \mathrm{C}$ for seven days in Yeast Mannitol (YM) liquid medium supplemented with an antibiotic when necessary [51]. Plant in vitro culture was performed in tubes filled with buffered nodulation medium (BNM) as described in Arrighi et al. [15]. Five-day-old plants were inoculated with $1 \mathrm{~mL}$ of bacterial culture with an adjusted OD at $600 \mathrm{~nm}$ to 1 . Twenty one days after inoculation, six plants were analysed for the presence of root nodules. Nitrogen-fixing activity was estimated on the entire plant by measurement of acetylene reducing activity (ARA) and microscopic observations were performed using a stereo-macroscope (Nikon AZ100, Champigny-sur-Marne, France) as published in Bonaldi et al. [50].

\section{Molecular methods}

Plant genomic DNA was isolated from fresh material using the classical CTAB (Cetyl Trimethyl Ammonium Bromide) extraction method. For herbarium material, the method was adapted by increasing the length of the incubation (90 $\mathrm{min})$, centrifugation $(20 \mathrm{~min})$ and precipitation $(15 \mathrm{~min})$ steps. The nuclear ribosomal internal transcribed spacer region (ITS), the chloroplast matK gene and four low-copy nuclear genes (CYP1, eiF1 $\alpha$, SuSy, and TIP1;1) previously identified in the A. evenia and $A$. afraspera transcriptomes were used for phylogenetic analyses [27, 28]. The genes were PCR-amplified, cloned and sequenced as described in Arrighi et al. [27] (Additional file 2: Table S2). For genomic DNA extracted from herbarium specimens, a battery of primers was developed to amplify the different genes in overlapping fragments as short as $250 \mathrm{bp}$ (Additional file 2: Table S2). The DNA sequences generated in this study were deposited in GenBank (Additional file 3: Table S3).

\section{Phylogenetic analyses and traits mapping}

Sequences were aligned using MAFFT (--localpair maxiterate 1000; [52]). Phylogenetic reconstructions were performed for each gene as well as for concatenated datasets under a Bayesian approach using Phylobayes 4.1b [53] and the site-heterogeneous CAT + F81 $+\Gamma 4$ evolution model. For each analysis, two independent chains were run for 10,000 Phylobayes cycles with a $50 \%$ burn-in. Ancestral states reconstruction was done through stochastic character mapping using the Phytools R package [54] running 10 simulations for each character.

\section{Species networks and hybridizations}

To test if the phylogeny obtained by concatenating the four low-copy nuclear genes (CYP1, eiF1 $\alpha, S u S y$, and
TIP1;1) was most likely obtained by gene duplications followed by differential losses or by a combination of duplications, losses coupled with one or several allopolyploidy events involving A. patula and Soemmeringia semperflorens, the method presented in [55] was used. In short, this method computes a reconciliation score by comparing a phylogenetic network and one or several gene trees. The method allows allopolyploidy events at hybridization nodes while all other nodes of the network are associated to speciation events; meanwhile, duplication and loss events are allowed at a cost (here, arbitrarily fixed to 1) on all nodes of the gene tree.

Thus, the set of 4 nuclear gene trees was used to score different phylogenetic networks corresponding to four different potential evolutionary histories. Two alternative networks with no reticulation corresponding to the two topologies obtained either with the group A (T1) or group B (T2) served to evaluate a no-allopolyploidisation hypothesis. The topology yielding the best score (T2) served to generate and compare all phylogenetic networks with one or two hybridization nodes, involving $A$. patula and/or S. semperflorens, to test successively a one-allopolyploidisation scenario (N1-best) and a two-allopolyploidisation evolutionary scenario (N2-best).

\section{GBS analysis}

A GBS library was constructed based on a protocol described [56]. For each sample, a total of $150 \mathrm{ng}$ of genomic DNA was digested using the two-enzyme system, PstI (rare cutter) and Mse (common cutter) (New England Biolabs, Hitchin, UK), by incubating at $37^{\circ} \mathrm{C}$ for $2 \mathrm{~h}$. The ligation reaction was performed using the $\mathrm{T} 4$ DNA ligase enzyme (New England Biolabs, Hitchin, UK) at $22^{\circ} \mathrm{C}$ for $30 \mathrm{~min}$ and the ligase was inactivated at $65^{\circ}$ $\mathrm{C}$ for $30 \mathrm{~min}$. Ligated samples were pooled and PCR-amplified using the Illumina Primer 1 (barcoded adapter with PstI overhang) and Illumina Primer 2 (common Y-adapter). The library was sequenced on an Illumina HiSeq $3000(1 \times 150 \mathrm{pb})$ (at the Get-PlaGe platform in Toulouse, France).

The raw sequence data were processed in the same way as in the study described in [57]. SNP calling from the raw Illumina reads was performed using the custom python pipeline VcfHunter (available at https://github.com/SouthGreenPlatform/VcfHunter/) (Guillaume Martin, CIRAD, France). For all samples, these sequence tags were aligned to the A. evenia 1.0 reference genome (JF Arrighi, unpublished data). The SNP results from all the samples were converted into one large file in VCF format and the polymorphism data were subsequently analyzed using the web-based application SNiPlay3 [58]. First, the SNP data were treated separately for each species and filtered out to remove SNP with more than $10 \%$ missing data as well as those with a minor allele frequency (MAF) 0.01 using 
integrated VCFtools. Second, an overall representation of the species diversity structures was obtained by making use of the PLINK software as implemented in SNiPlay3. This software is based on the multidimensional-scaling (MSD) method to produce two-dimensional plots.

\section{Genome size estimation and chromosome counting}

Genome sizes were measured by flow cytometry using leaf material as described in Arrighi et al. [15]. Genome size estimations resulted from measurements of three plants per accession and Lycopersicum esculentum (Solanaceae) cv "Roma" $(2 \mathrm{C}=1.99 \mathrm{pg})$ was used as the internal standard. The $1 \mathrm{C}$ value was calculated and the conversion factor $1 \mathrm{pg} \mathrm{DNA}=978 \mathrm{Mb}$ was used to express it in $\mathrm{Mb} / 1 \mathrm{C}$. To count chromosome number, metaphasic chromosomes were prepared from root-tips, spread on slides, stained with 4',6-diamidino-2-phenylindole (DAPI) and their image captured with a fluorescent microscope as detailed in Arrighi et al. [15] .

\section{Additional files}

Additional file 1: Table S1. Accessions used for the phylogeny of the genus Aeschynomene and related genera, their origin and characteristics. (PPTX $143 \mathrm{~kb}$ )

Additional file 2: Table S2. Primers used for gene amplification and sequencing. (PPTX $134 \mathrm{~kb}$ )

Additional file 3: Table S3. GenBank numbers for the sequences used in the phylogenetic analyses. (PPTX $149 \mathrm{~kb}$ )

Additional file 4: Figure S1. matK phylogeny of the genus Aeschynomene and allied genera. Bayesian phylogenetic reconstruction obtained using the chloroplastic matk gene. Numbers at branches are posterior probability. (PPTX $133 \mathrm{~kb}$ )

Additional file 5: Figure S2. ITS phylogeny of the genus Aeschynomene and allied genera. Bayesian phylogenetic reconstruction obtained using the Internal Transcribed Spacer (ITS) sequence. Numbers at branches are posterior probability. (PPTX $134 \mathrm{~kb}$ )

Additional file 6: Figure S3. Chromosome numbers in Aeschynomene species. Root tip metaphase chromosomes stained in blue with DAPI (4,6-diamidino-2-phenylindole). Chromosome numbers are indicated in brackets. Scale bars: $5 \mu \mathrm{m}$. (PPTX $135 \mathrm{~kb}$ )

Additional file 7: Figure S4. Chromosome numbers in species of Aeschynomene related genera. Root tip metaphase chromosomes stained in blue with DAPI (4',6-diamidino-2-phenylindole). Chromosome counts are indicated in brackets. Scale bars: $5 \mu \mathrm{m}$. (PPTX $57 \mathrm{~kb}$ )

Additional file 8: Figure S5. Phylogenetic trees based on nuclear lowcopy genes. Bayesian phylogenetic reconstructions obtained for the CYP1, eif1a, SuSy and TIP1;1 genes. Diploid species $(2 n=20)$ are in blue, polyploid species $(2 n \geq 28)$ in black excepted $A$. afraspera for which the $A$ and $B$ gene copies are distinguished in red and green respectively. $-A$, $-A 1,-A 2,-B,-B 1$ and $-B 2$ indicated the different copies found. Putative $A$ and $B$ subgenomes of the polyploid taxa are delineated by red and green boxes in dashed lines, respectively. Numbers at branches represent posterior probability. (PPTX $56 \mathrm{~kb}$ )

Additional file 9: Figure S6. Ancestral state reconstruction of ploidy levels in the genus Aeschynomene and allied genera. Ancestral state reconstruction was estimated in SIMMAP software using the 50\% majority-rule topology obtained by Bayesian analysis of the combined ITS + matK sequences. Ploidy levels are indicated by different colors. Unknown ploidy levels are denoted by a dash. (PPTX 3568 kb)
Additional file 10: Figure S7. Phylogenetic networks based on the four nuclear CYP1, eif1a, SuSy and TIP1;1 genes. (a) No-allopolyploidisation hypothesis (T1) based on the concatenated gene tree obtained taking into account the group A (Fig. 2b). (b) No-allopolyploidisation hypothesis (T2) based on the concatenated gene tree obtained taking into account the group B (Fig. 2b). (c) One-allopolyploidisation hypothesis (N1-best). (d) Two-allopolyploidisation hypothesis (N2-best). Blue lines indicate reticulations while other nods of the network are associated to speciation events. Scores obtained for the different phylogenetic networks are indicated. (PPTX $2589 \mathrm{~kb}$ )

Additional file 11: Figure S8. Ancestral state reconstruction of adventive root primordia in the genus Aeschynomene and allied genera. Ancestral state reconstruction was estimated in SIMMAP software using the $50 \%$ majority-rule topology obtained by Bayesian analysis of the combined ITS + matK sequences. Data on the adventitious root primordia come from the present analysis and pertinent previously published data. Presence or not of adventitious root primordia is indicated by different colors. (PPTX $96 \mathrm{~kb}$ )

Additional file 12: Figure S9. Ancestral state reconstruction of ecological habit in the genus Aeschynomene and allied genera. Ancestral state reconstruction was estimated in SIMMAP software using the 50\% majority-rule topology obtained by Bayesian analysis of the combined ITS + matK sequences. Data on the species ecology come from pertinent previously published data. Ecological habits are indicated by different colors. (PPTX $135 \mathrm{~kb}$ )

Additional file 13: Figure S10. Ancestral state reconstruction of the aerial stem nodulation ability in the genus Aeschynomene and allied genera. Ancestral state reconstruction was estimated in SIMMAP software using the $50 \%$ majority-rule topology obtained by Bayesian analysis of the combined ITS + matK sequences. Data on the occurrence of stem nodulation come from pertinent previously published data. Occurrence or not of stem nodulation is indicated by different colors. (XLSX $15 \mathrm{~kb}$ )

Additional file 14: Figure S11. Ancestral state reconstruction of the ability to nodulate with the photosynthetic Bradyrhizobium strains in the genus Aeschynomene and allied genera. Ancestral state reconstruction was estimated in SIMMAP software using the 50\% majority-rule topology obtained by Bayesian analysis of the combined ITS + matK sequences. Data on nodulation with photosynthetic Bradyrhizobium strains come from the present analysis and pertinent previously published data. Nodulation with photosynthetic Bradyrhizobium strains is considered positive only if reported as occurring naturally or being efficient in vitro. (XLSX 13 $\mathrm{kb})$

Additional file 15: Figure S12. Ancestral state reconstruction of the ability to nodulate with the photosynthetic Bradyrhizobium strain ORS278 in the genus Aeschynomene and allied genera. Ancestral state reconstruction was estimated in SIMMAP software using the 50\% majority-rule topology obtained by Bayesian analysis of the combined ITS + matK sequences. Data on nodulation with ORS278 come from the present analysis and pertinent previously published data. Ability or not to nodulate with ORS278 is indicated by different colors. (XLSX 16 kb) (XLSX $11 \mathrm{~kb})$

Additional file 16: Table S4. A. americana and A. villosa accessions used for the GBS analysis, their origin and characteristics. (XLSX $16 \mathrm{~kb}$ )

\section{Abbreviations}

ARA: Acetylene reduction assay; BNM: Buffered nodulation medium; BRH: Clade containing Aeschynomene subgenera Bakerophyton and Rueppellia together with the genus Humularia; Cl: Cross-inoculation; DAPI: 4',6diamidino-2-phenylindole; dpi: Days-post-germination; GBS: Genotyping-bysequencing; MSD: Multidimensional-scaling; PP: Posterior probability; SNP: Single nucleotide polymorphism; T3SS: Type III secretion system; YM: Yeast medium

\section{Acknowledgements}

We thank the different seed banks and herbaria for provision of seeds and herbarium vouchers that were used in this study. The present work has benefited from the facilities and expertise of the cytometry facilities of Imagerie-Gif (http://www.i2bc.paris-saclay.fr/spip.php?article279) and of the 
molecular cytogenetic facilities of the AGAP laboratory (http://umr-agap.cirad.fr/en/plateformes/plateau-de-cytogenetique-moleculaire).

\section{Funding}

This work was supported by a grant from the French National Research Agency (ANR-AeschyNod-14-CE19-0005-01) that served for the design of the study, experimentation and analysis of the data.

\section{Availability of data and materials}

The gene sequences generated in this study were deposited in GenBank (accession numbers listed in Table S3). The Illumina HiSeq 3000 sequencing raw data are available in the NCBI SRA (Sequence Read Archive) under the study accession number: SRP149516. All additional data are included in this published article as supplementary information files.

\section{Authors' contributions}

JFA designed the experiments. $L B, C C, R R$, JF, SCB, MGP, MB, CH, MD and JFA performed the experiments and obtained the data. PS, CS, LM undertook the phylogenetic analyses. PM, JQ, GPL, AD'H, EG and JFA analysed the data. MG, $R D, H R 1, H R 2, H V$ and $M Z$ contributed to the acquisition and analysis of accessions. JFA wrote the paper. LB and CC contributed equally. All authors read and approved the final manuscript.

\section{Ethics approval and consent to participate}

The sources of the accessions used in this study are indicated in Additional file 1: Table S1 and Additional file 16: Table S4.

\section{Consent for publication}

Not applicable

\section{Competing interests}

The authors declare that they have no competing interests.

\section{Publisher's Note}

Springer Nature remains neutral with regard to jurisdictional claims in published maps and institutional affiliations.

\begin{abstract}
Author details
${ }^{1}$ IRD, Laboratoire des Symbioses Tropicales et Méditerranéennes, UMR LSTM, Campus International de Baillarguet, 34398 Montpellier, France. ${ }^{2}$ Institut des Sciences de l'Evolution (ISE-M), Université de Montpellier, CNRS, IRD, EPHE, 34095 Cedex 5 Montpellier, France. ${ }^{3}$ CIRAD (Centre de Coopération Internationale en Recherche Agronomique pour le Développement), UMR AGAP, F-34398 Montpellier, France. ${ }^{4}$ AGAP, Univ Montpellier, CIRAD, INRA, Montpellier SupAgro, 34060 Montpellier, France. ${ }^{5}$ IRD, Interactions Plantes Microorganismes Environnement, UMR IPME, 34394 Montpellier, France. ${ }^{6}$ Comparative Plant and Fungal Biology Department, Royal Botanic Gardens, Kew, Richmond, Surrey TW9 3AB, UK. Institute of Integrative Biology of the Cell (I2BC), CEA, CNRS, Univ. Paris-Sud, Université Paris-Saclay, 91198 Gif-sur-Yvette, France. ${ }^{8}$ Laboratoire de Botanique, Institut Fondamental d'Afrique Noire, Ch. A. Diop, BP 206 Dakar, Sénégal. 'Laboratoire de Microbiologie de l'Environnement/Centre National de Recherche sur I'Environnement, 101 Antananarivo, Madagascar. ${ }^{10}$ IAC, Laboratoire de Botanique et d'Ecologie Végétale Appliquée, UMR AMAP, 98825 Pouembout, Nouvelle-Calédonie, France. ${ }^{11}$ Department of Biochemistry and Microbial Genomics, IIBCE, 11600 Montevideo, Uruguay. ${ }^{12}$ Department of Biochemistry, University of Calcutta, Kolkata 700019, India.
\end{abstract}

\section{Received: 1 October 2018 Accepted: 23 November 2018} Published online: 05 December 2018

\section{References}

1. Hagerup O. En hygrofil baelgplante (Aeschynomene aspera L.) med bakterieknolde paa staenglen. Dansk Bot. Arkiv. 1928:4:1-9.

2. Alazard D. Stem and root nodulation in Aeschynomene spp. Appl Environ Microbiol. 1985:50:732-4.

3. Boivin C, Ndoye I, Molouba F, De Lajudie P, Dupuy N, Dreyfus B. Stem nodulation in legumes: diversity, mechanisms, and unusual characteristics. Crit Rev Plant Sci. 1997;16:1-30
4. Chaintreuil C, Arrighi JF, Giraud E, Miché L, Moulin L, Dreyfus B, et al. Evolution of symbiosis in the legume genus Aeschynomene. New Phytol. 2013;200:1247-59

5. Giraud E, Hannibal L, Fardoux J, Vermeglio A, Dreyfus B. Effect of Bradyrhizobium photosynthesis on stem nodulation of Aeschynomene sensitiva. PNAS. 2000:97:14795-800.

6. Miché L, Moulin L, Chaintreuil C, Contreras-Jimenez JL, Munive-Hernandez JA, Del Carmen V-HM, et al. Diversity analyses of Aeschynomene symbionts in tropical Africa and Central America reveal that nod-independent stem nodulation is not restricted to photosynthetic bradyrhizobia. Environ Microbiol. 2010;12:2152-64

7. Giraud E, Moulin L, Vallenet D, Barbe V, Cytryn E, Avarre JC, et al. Legumes symbioses: absence of nod genes in photosynthetic bradyrhizobia. Science. 2007;316:1307-12

8. Okazaki S, Kaneko T, Sato S, Saeki K. Hijacking of leguminous nodulation signaling by the rhizobial type III secretion system. PNAS. 2013;110:17131-6.

9. Okazaki S, Tittabutr P, Teulet A, Thouin J, Fardoux J, Chaintreuil C, et al. Rhizobium-legume symbiosis in the absence of nod factors: two possible scenarios with or without the T3SS. ISME J. 2015;10:64-74.

10. Sprent JI, Ardley J, James EK. Biogeography of nodulated legumes and their nitrogen-fixing symbionts. New Phytol. 2017:215:40-56.

11. Sprent Jl, James EK. Legume-rhizobial symbiosis: an anorexic model? New Phytol. 2008;179:3-5.

12. Madsen $L H$, Tirichine $L$, Jurkiewicz A, Sullivan JT, Heckmann AB, Bek AS, et al. The molecular network governing nodule organogenesis and infection in the model legume Lotus japonicus. Nature Com. 2010;1:10.

13. Okubo T, Fukushima S, Minamisawa K. Evolution of BradyrhizobiumAeschynomene mutualism: living testimony of the ancient world or highly evolved state? Plant \& Cell Physiology. 2012;53:2000-7.

14. Czernic P, Gully D, Cartieaux F, Moulin L, Guefrachi I, Patrel D, et al. Convergent evolution of endosymbiont differentiation in Dalbergioid and inverted repeat-lacking clade legumes mediated by nodule-specific cysteine-rich peptides. Plant Physiol. 2015;169:1254-65.

15. Arrighi JF, Cartieaux F, Brown SC, Rodier-Goud M, Boursot M, Fardoux J, et al. Aeschynomene evenia, a model Plant for Studying the molecular genetics of the nod-independent rhizobium-legume Symbiosis. MPMI. 2012;25:85161.

16. Arrighi JF, Cartieaux F, Chaintreuil C, Brown SC, Boursot M, Giraud E. Genotype delimitation in the nod-independent model legume Aeschynomene evenia. PLoS One. 2013;8:e63836.

17. Arrighi JF, Cartieaux F. Out of water of a new model legume: the Nodindependent Aeschynomene evenia. In Biological Nitrogen Fixation, Vol 2 Ed. de Bruijn. Wiley-Blackwell publishers. 2015. Chapter 45,447-54.

18. Fabre S, Gully D, Poitout A, Patrel D, Arrighi JF, Giraud E, et al. Nod factorindependent nodulation in Aeschynomene evenia required the common plant-microbe symbiotic toolkit. Plant Physiol. 2015;169:2654-64.

19. Chaintreuil C, Rivallan R, Bertioli DJ, Klopp C, Gouzy J, Courtois B, et al. A gene-based map of the nod factor-independent Aeschynomene evenia sheds new light on the evolution of nodulation and legume genomes. DNA Res. 2016;23:365-76.

20. Nouwen N, Arrighi JF, Cartieaux F, Gully D, Klopp C, Giraud E. The role of rhizobial (NifV) and plant (FEN1) homocitrate synthesis in Aeschynomene photosynthetic Bradyrhizobium symbiosis. Sci Rep. 2017:7:448.

21. Rudd VE. The American species of Aeschynomene. Contributions of the United States National Herbarium. 1955:32:1-172.

22. Gillett JB, Polhill RM, Verdcourt B. Leguminosae (part 3): subfamily Papilionoideae (part 1). In: Milne-Redhead E, Polhill RM, editors. Flora of tropical East Africa. Kew: Royal Botanic Gardens; 1971.

23. Rudd VE. Aeschynomeneae. In: Polhill RM, Raven PH eds. Advances in legume systematics. Kew: Royal Botanic Gardens. 1981. Part1: 347-354.

24. Lavin M, Pennington RT, Klitgaard BB, Sprent Jl, de Lima HC, Gasson PE. The dalbergioid legumes (Fabaceae): delimitation of a pantropical monophyletic clade. Am J Bot. 2001;88:503-33.

25. Klitgaard BB, Lavin M. Tribe Dalbergieae sens. lat. In: Lewis G, et al., editors. Legumes of the world. Kew: Royal Botanic Gardens; 2005. p. 307-35.

26. LPWG (The Legume Phylogeny Working Group). A new subfamily classification of the Leguminosae based on a taxonomically comprehensive phylogeny. Taxon. 2017:66:44-77.

27. Arrighi JF, Chaintreuil C, Cartieaux F, Cardi C, Rodier-Goud M, Brown SC, et al. Radiation of the nod-independent Aeschynomene relies on multiple allopolyploid speciation events. New Phytol. 2014;201:1457-68. 
28. Chaintreuil C, Gully J, Hervouet C, Tittabutr P, Randriambanona H, Brown SC, et al. The evolutionary dynamics of ancient and recent polyploidy in the African semi-aquatic species of the legume genus Aeschynomene. New Phytol. 2016;211:1077-91.

29. Chaintreuil C, Perrier X, Martin G, Fardoux J, Lewis GP, Brottier L, et al. Naturally occurring variations in the nod-independent model legume Aeschynomene evenia and relatives: a resource for nodulation genetics. BMC Plant Biol. 2018;18(1):54.

30. Lewis G, Schrire B, Mackinder B, Lock M. Legumes of the world. Kew: Royal Botanic Gardens; 2005

31. Du Puy DJ, Labat J-N, Rabevohitra R, Villiers J-F, Bosser J, Moat J. The Leguminosae of Madagascar. Kew: Royal Botanic Gardens; 2002.

32. Lock JM. Legumes of Africa. Royal Botanic Gardens, Kew, England: A checklist; 1989.

33. Loureiro MF, De Faria SM, James EK, Pott A, Franco AA. Nitrogen-fixing stem nodules of the legume, Discolobium Pulchellum Benth. New Phytol. 1994; 128:283-95.

34. Loureiro MF, James EK, Sprent Jl, Franco AA. Stem and root nodules on the tropical wetland legume Aeschynomene fluminensis. New Phytol. 1995; 30:531-44.

35. Alazard D, Duhoux E. Nitrogen-fixing stem nodules on Aeschynomene afraspera. Biological fertility Soils. 1987;4:61-6.

36. Cook, B.G., Pengelly, B.C., Brown, S.D., Donnelly, J.L., Eagles, D.A., Franco, M.A., Hanson, J., Mullen, B.F., Partridge, I.J., Peters, M., Schultze-Kraft R. Tropical Forages: an interactive selection tool. CSIRO, DPI\&F(QId), CIAT and ILRI, Brisbane, Australia. 2005. http://www.tropicalforages.info.

37. Govindarajulu R, Hughes CE, Alexander PJ, Bailey CD. The complex evolutionary dynamics of ancient and recent polyploidy in Leucaena (Leguminosae; Mimosoideae). Am J Bot. 2011;98(12):2064-76.

38. Okuyama Y, Tanabe AS, Kato M. Distangling ancient allotetraploidization in Asian Mitella: an integrated approach for multilocus combinations. Mol Biol Evol. 2012;29:429-39.

39. Whitfield JB, Lockhart PJ. Deciphering ancient rapid radiations. Trends Ecol Evol. 2007;22:258-65

40. Molouba F, Lorquin J, Willems A, Hoste B, Giraud E, Dreyfus B, et al. Photosynthetic bradyrhizobia from Aeschynomene spp. are specific to stemnodulated species and form a separate 165 ribosomal DNA restriction fragment length polymorphism group. Appl Environ Microbiol. 1997;65: 3084-94.

41. Delaux PM, Varala K, Edger PP, Coruzzi GM, Pires JC, Ané JM. Comparative phylogenomics uncovers the impact of symbiotic associations on host genome evolution. PLoS Genet. 2041;10:e1004487.

42. Bravo A, York T, Pumplin N, Mueller LA, Harrison MJ. Genes conserved for arbuscular mycorrhizal symbiosis identified through phylogenomics. Nat Plants. 2016:18:15208.

43. Delaux PM, Radhakrishnan G, Oldroyd G. Tracing the evolutionary path to nitrogen-fixing crops. Cur Opi Plant Bio. 2015;26:95-9.

44. Griesmann M, Chang Y, Liu X, Song Y, Haberer G, Crook MB et al. Phylogenomics reveals multiple losses of nitrogen-fixing root nodule symbiosis. Science. 2018;361(6398). https://doi.org/10.1126/science.aat1743.

45. Geurts R, Xiao TT, Reinhold-Hurek B. What does it take to evolve a nitrogenfixing endosymbiosis? Trends Plant Sci. 2016;21:199-208.

46. Behm JE, Geurts R, Kiers ET. Parasponia: a novel system for studying mutualism stability. Trends Plant Sci. 2014;19:757-63.

47. van Velzen R, Holmer R, Bu F, Rutten L, van Zeijl A, Liu W, et al. Comparative genomics of the nonlegume Parasponia reveals insights into evolution of nitrogen-fixing rhizobium symbioses. PNAS. 2018;115(20):E4700-9.

48. Noisangiam R, Teamtisong K, Tittabutr P, Boonkerd N, Toshiki U, Minamisawa K, Teaumroong N. Genetic diversity, symbiotic evolution, and proposed infection process of Bradyrhizobium strains isolated from root nodules of Aeschynomene americana L. in Thailand. Appl Environ Microbiol. 2012;78(17):6236-50.

49. Teamtisong K, Songwattana P, Noisangiam R, Piromyou P, Boonkerd N, Tittabutr $P$, et al. Divergent nod-containing Bradyrhizobium sp. DOA9 with a megaplasmid and its host range. Microbes Environ. 2014;29:370-6.

50. Bonaldi K, Gargani D, Prin Y, Fardoux J, Gully D, Nouwen N, et al. Nodulation of Aeschynomene afraspera and A. indica by photosynthetic Bradyrhizobium sp. strain ORS285: the nod-dependent versus the nodindependent symbiotic interaction. MPMI. 2011;24:1359-71.

51. Howieson J.G. and Dilworth M.J. (Eds.). Working with rhizobia. Australian Centre for International Agricultural Research: Canberra. 2016.
52. Katoh K, Standley DM. MAFFT multiple sequence alignment software version 7: improvements in performance and usability. Mol Biol Evol. 2013; 30(4):772-80.

53. Lartillot N, Philippe H. A Bayesian mixture model for across-site heterogeneities in the amino-acid replacement process. Mol Biol Evol. 2004; 21(6):1095-109.

54. Revell LJ. Phytools: an R package for phylogenetic comparative biology (and other things). Methods Ecol Evol. 2012;3:217-23.

55. To TH, Scornavacca C. Efficient algorithms for reconciling gene trees and species networks via duplication and loss events. BMC Genomics. 2015; 16(Suppl 10):S6

56. Oueslati A, Salhi-Hannachi A, Luro F, Vignes H, Mournet $P$, Ollitrault $P$. Genotyping by sequencing reveals the interspecific C. maxima / C. reticulata admixture along the genomes of modern citrus varieties of mandarins, tangors, tangelos, orangelos and grapefruits. PLoS One. 2017:12(10): e0185618.

57. Garsmeur O, Droc G, Antonise R, Grimwood J, Potier B, Aitken K, et al. A mosaic monoploid reference sequence for the highly complex genome of sugarcane. Nat Commun. 2018;9:2638.

58. Dereeper A, Homa F, Andres G, Sempere G, Sarah G, Hueber Y, et al. SNiPlay3: a web-based application for exploration and large scale analyses of genomic variations. Nucleic Acids Res. 2015:43(W1):W295-300.

\section{Ready to submit your research? Choose BMC and benefit from:}

- fast, convenient online submission

- thorough peer review by experienced researchers in your field

- rapid publication on acceptance

- support for research data, including large and complex data types

- gold Open Access which fosters wider collaboration and increased citations

- maximum visibility for your research: over $100 \mathrm{M}$ website views per year

At BMC, research is always in progress.

Learn more biomedcentral.com/submissions 